\title{
PROBLEMATISASI KELOMPOK SUBALTERN DAN AMERICAN DREAM DALAM NOVEL THE BUDDHA IN THE ATTIC KARYA JULIE OTSUKA
}

Problematizing The Subalterns and The American Dream in Julie Otsuka's The Buddha in the Attic

\author{
Sindhy Sintya Mianani \\ Program Studi Magister Kajian Sastra dan Budaya \\ Fakultas Imu Budaya, Universitas Airlangga \\ Address: Jl. Dharmawangsa Dalam Selatan, Kampus B, Surabaya, Indonesia 60286 \\ Surel: sindhysintya@gmail.com
}

\begin{abstract}
Abstrak: Novel The Buddha in the Attic karya Julie Otsuka merupakan novel yang memuat fenomena migrasi para perempuan Jepang sebagai picture brides di Amerika Serikat. Berawal dari sebuah foto yang menyimbolkan kesuksesan American Dream, para perempuan ini mengadu nasib di daratan yang selama ini dikenal dengan gaung kesuksesan yang ditawarkan oleh American Dream. Akan tetapi, para picture brides, termasuk para imigran Jepang di Amerika, mengalami diskriminasi rasial. Dari kondisi ini, muncul sebuah permasalahan lain yang dialami oleh picture brides, termasuk didalamnya para imigran Jepang, yang mengalami kesusahan dalam mendapatkan kesempatan memperoleh kesuksesan di Amerika. Isu ini kemudian mengarah ke permasalahan yang lebih mendalam, yaitu mengenai problematika American Dream dari sudut pandang picture brides dengan American Dream dari sudut pandang warga Amerika itu sendiri. Untuk menjawab permasalahan tersebut, studi ini menerapkan teori subaltern milik Gayatri Spivak sebagai kerangka pemikiran teoretis. Berdasarkan hasil analisis, nampak bahwa ada fenomena propaganda American Dream yang mereduksi nilai-nilai American Dream. American Dream yang menekankan life, liberty dan the pursuit of happiness layaknya tercantum dalam The Declaration of Independence pada kenyataannya digunakan sebagai agenda politik oleh pemerintah Amerika Serikat untuk menjaga homogenitas budaya masyarakat Amerika.
\end{abstract}

Kata Kunci: American Dream, Picture Brides Jepang, Propaganda, Subaltern

Abstract: Julie Otsuka's The Buddha in the Attic is a novel telling the migration phenomenon of Japanese women as picture brides in The United States of America. It does all begin with a picture which serves as the symbol of American Dream's fruitful stories. These pictures entice these Japanese women to seek for a better future in a land full of its grand stories of the American Dream. However, these picture brides as well as the Japanese immigrants in the USA, face racial discrimination. This condition leads to the issue experienced by those picture brides, as well as the Japanese immigrants, who struggle to get an opportunity to be successful in America. This issue eventually leads to the problematizing phenomenon of The American Dream seen from the picture brides' point of view and The American Dream from the Americans' point of view. To answer the issues aforementioned, this study applies Gayatri Spivak's notion on subaltern as the theoretical framework. The results of this study show that there is a propaganda phenomenon of The American Dream which reduce its original values. American Dream, which always emphasizes on life, liberty and the pursuit of happiness as stated in The Declaration of

(C2021 Sindhy Sintya Mianani. Published in Lakon: Jurnal Kajian Sastra dan Budaya. Published by Universitas Airlangga. This article is published under the Creative Commons Attribution (CC BY-NC-SA 4.0) lisence. 
Independence, is served as a political means to keep the homogeneity culture of the Americans.

Keywords: American Dream, Japanese Picture Brides, Propaganda, Subaltern

\section{PENDAHULUAN}

Amerika Serikat selama ini dikenal sebagai The New World yang terkenal dengan gaung kesuksesan yang ditawarkan oleh American Dream. Dengan jargonnya yang menggaungkan bahwa semua orang pada dasarnya diciptakan setara, sehingga mereka diberkati oleh Sang Pencipta dengan hak-hak yang tidak dapat diganggu gugat, termasuk didalamnya adalah hak untuk hidup, hak untuk memiliki kebebasan, dan hak untuk menggapai kebahagiaan (Jefferson, 1776 , p. 1), ia menarik jutaan imigran ke daratan Amerika Serikat. Berdasarkan konsep Jefferson ini, American Dream secara sederhana dipahami sebagai sebuah kepercayaan (belief) bahwa semua individu memiliki kesempatan yang setara untuk mencapai kesuksesan dan kebahagiaan. American Dream juga dapat didefinisikan sebagai hak-hak untuk mewujudkan harapan dan impian tiap-tiap individu.

Istilah American Dream sendiri pertama kali dikenalkan oleh sejarawan James Truslow Adams dalam bukunya yang berjudul The Epic of America (1931). Salah satu kutipan yang paling sering digunakan sebagai justifikasi untuk mendefinisikan American Dream ialah "sebuah impian tentang tempat dimana kehidupan seharusnya [dapat] lebih baik, lebih kaya, dan lebih mapan bagi semua orang, dilengkapi dengan kesempatan bagi setiap orang berdasarkan kemampuan dan pencapaian masing-masing" (Adams, 1931, p. 215).

Bagi para imigran, Amerika merupakan sebuah daratan baru sekaligus sebuah suaka yang menawarkan kesempatan untuk menggapai impian dan harapan mereka yang tertunda di tanah asal mereka. Sebabnya, tawaran memperoleh kesuksesan menjadi daya tarik utama dari American Dream bagi siapapun yang datang ke Amerika. Fenomena migrasi di Amerika Serikat sendiri sejatinya diawali oleh ketiga belas koloni dari Inggris yang terdiri dari kelompok Puritans dan Pilgrims (Hallam, 2004). Selain migrasi warga Eropa, dari praktek perbudakan warga Afrika yang dilakukan oleh ketiga belas koloni juga menandai adanya fenomena migrasi warga Afrika ke Amerika. Selain migrasi dari bangsa Eropa dan Afrika, terdapat pula fenomena migrasi warga Asia yang meliputi warga negara Filipina, India, China, Korea maupun Jepang. Fenomena diaspora warga Asia di Amerika mayoritas didasari oleh alasan pekerjaan. Kesempatan kerja inilah yang mendorong sebagian besar warga Asia mengadu nasib di daratan Amerika (Okihiro, 2001).Selain faktor pekerjaan, salah satu penyebab fenomena migrasi warga Asia ke Amerika ialah picture marriage pada masa Perang Dunia II, khususnya bagi para perempuan yang berasal dari Cina, Korea dan Jepang. Dengan bermodalkan foto "riil" calon suami mereka, para picture brides menjalani perjalanan yang jauh dan rumit untuk menemui suami mereka. Perempuan- 
perempuan ini memiliki anggapan bahwa lebih baik menikah dengan laki-laki yang sebelumnya tidak mereka kenal daripada hidup miskin di Jepang. Foto-foto yang digunakan untuk menunjukkan profil calon suami mereka inilah yang menyimbolkan Amerika Serikat sebagai negara dengan sejuta harapan, sesuai dengan karakteristik-karakteristik yang terkandung dalam American Dream. Fenomena ini kemudian dimanifestasikan oleh seorang pengarang Amerika keturunan Jepang, Julie Otsuka, dalam novelnya yang berjudul The Buddha in the Attic. The Buddha in the Attic menceritakan pengalaman perempuan-perempuan Jepang yang mencoba peruntungan dengan menjadi picture brides $\mathrm{di}$ Amerika. Mereka berharap dengan pindah ke Amerika Serikat, mereka dapat memperbaiki kehidupan mereka. Mereka yakin bahwa Amerika merupakan suaka bagi mereka yang ingin mewujudkan impian-impian yang selama ini belum sempat terwujudkan layaknya tawaran dari American Dream selama ini. Akan tetapi, perbedaan ras, budaya dan keterbatasan bahasa menjadi penghalang bagi para perempuan ini untuk dapat mewujudkan impian mereka. Selain mengalami berbagai rintangan dalam mewujudkan impian mereka, para picture brides dan juga imigran Jepang juga dianggap sebagai sosok alien dikalangan masyarakat Amerika. Adanya stereotype rasial terhadap imigran Jepang menyebabkan pandangan sebelah mata dan marginalitas terhadap kelompok imigran Jepang. Kondisi ini juga dikenal dengan istilah kelompok subaltern.
Dengan memperhatikan permasalahan tersebut, studi ini berfokus kepada bagaimana American Dream, yang dilihat dari sudut pandang para Japanese picture brides dan juga imigran Jepang di Amerika Serikat, berubah menjadi sebuah bentuk propaganda yang digunakan oleh pemerintah Amerika Serikat untuk menjaga homogenitas budaya Amerika. Dengan menilik fakta bahwa fenomena negasi identitas sangat menonjol dalam novel ini, maka untuk memperoleh hasil diskusi yang rigid, penelitian ini memanfaatkan teori subaltern yang dikembangkan oleh Gayatri Spivak.

\section{LANDASAN TEORI}

Untuk menjawab permasalahan seperti yang telah dipaparkan pada bagian sebelumnya, studi ini menerapkan teori subaltern milik Gayatri Spivak. Teori ini dipilih karena dianggap paling sesuai untuk menjadi alat bantu analisis penelitian yang fokus pada konsep hegemoni. Hegemoni merupakan sebuah bentuk dominasi yang dilakukan oleh kelompok dominan (dominant groups) dan sepenuhnya dilakukan melalui persetujuan aktif dari kelompokkelompok yang dikuasai (subordinate groups). Dengan kata lain, hegemoni tidak sepenuhnya melibatkan kekerasan. Dalam pengertian ini, persetujuan dari kelompok-kelompok yang dikuasai bukanlah kesadaran palsu (false consciousness) tetapi sikap penerimaan mereka atas legitimasi tatanan sosial dan politik sebagai sebuah praktik nyata.

Sebagai sebuah proses,
hegemoni juga akan selalu
berhubungan dengan struktur
kehidupan sehari-hari yang selalu
berkaitan dengan makna historis yang 
kuat karena secara sosiologis, ia memiliki hubungan konkret dengan formasi kelas sosial, sejarah dan karena ia merupakan proses yang melibatkan subjek yang aktif dalam wacana praktis sehari-hari. Hegemoni juga akan selalu berhubungan dengan distribusi kekuasan dan pengaruh yang spesifik terhadap kelompok yang dikuasai (Williams, 1977). Hegemoni pada akhirnya, seperti halnya tradisi, menjaga kesinambungan budaya dan sejarah.

Konsep hegemoni inilah yang menjadi dasar pemikiran Spivak dalam konsep subaltern. Apabila dikaitkan dengan konsep hegemoni yang pada dasarnya melanggengkan kebudayaan dan tradisi dari kelompok yang dominan, hegemoni juga berkaitan erat dengan konsep subaltern. Dari konsep hegemoni kultural yang dikenalkan oleh Antonio Gramsci ini, Spivak mengadaptasi konsep subaltern ini untuk menyebut kelompok-kelompok yang berbeda yaitu the others. Penggunaan istilah subaltern juga merujuk kepada pada segala sesuatu yang terkait dengan pembatasan akses yang menimbulkan sebuah ruang pembedaan bagi kelompok the others. Masalah pembatasan akses dan ruang pembedaan terhadap the others tidak hanya meliputi kategori orang yang tertindas atau kelas pekerja yang tertindas saja, namun juga meliputi siapa saja yang suaranya terbatasi oleh pihak-pihak yang bersifat merepresen-tasikan subaltern (Spivak, 1994).

Spivak juga menegaskan bahwa subaltern sebagai the others dipengaruhi oleh relasi kuasa antara kelompok dominan sebagai the Others. Dengan adanya relasi kuasa, kelompok subaltern sebagai the others mengalami pengecualian. Sebabnya, dalam relasi kuasa ini secara tidak langsung muncul proses othering yang memungkinkan adanya proses dialektikal antara budaya kelompok dominan dengan kelompok subaltern (Spivak, 1994). Proses othering ini menciptakan sudut pandang yang saling menegasi identitas satu sama lain. Kelompok subaltern sebagai the others dipandang sebagai sosok subjek yang sudah selayaknya tunduk pada kelompok the Others yang lebih dominan. Sedangkan kelompok subaltern berusaha mengadaptasi kebudayaan kelompok dominan dengan harapan mendapatkan validasi. Dengan adanya anggapan bahwa budaya dominan adalah sebuah norma, kelompok subaltern ini, mau tidak mau, akhirnya mengadaptasi budaya dominan. Dari proses othering ini, secara tidak langsung, homogenitas budaya kelompok dominan dilanggengkan.

\section{METODE}

Studi ini menggunakan pendekatan kualitatif deskriptif dalam menjawab rumusan permasalahan yang sebelumnya telah dipaparkan. Menurut Ratna (2015, p. 47), metode kualitatif memberikan perhatian kepada data alamiah, yaitu data dalam hubungannya dengan konteks keberadaannya. Senada dengan pendapat Ratna, Creswell (2007, p. 5) menambahkan bahwa nantinya, data yang didapatkan akan disajikan dalam bentuk deskripsi dengan menggunakan analisis teks dan konteks. Deskripsi ini kemudian disertai dengan penafsiran yang menjadi ciri khas utama dalam 
penelitian berbasis metode kualitatif deskriptif.

Objek material studi ini adalah novel berjudul The Buddha in the Attic yang sekaligus berfungsi sebagai data primer dalam studi ini. Pada tahap penentuan dan pemahaman objek, pembacaan mendalam terhadap novel dilakukan. Kemudian, pada tahap pemahaman teks yang lebih intensif, ditemukan problematika yang menjadi fokus studi, yaitu isu mengenai kelompok imigran Jepang sebagai the subaltern dan reduksi nilai-nilai American Dream. Pada tahapan selanjutnya, pengumpulan data-data dilakukan. Data-data ini berupa kutipan-kutipan novel dan juga fenomena sejarah yang relevan. Setelah data-data terkumpul, identifikasi terhadap data-data dilakukan dengan bantuan teori subaltern milik Gayatri Spivak. Memasuki tahap analisis data dan pemaknaan, penelitian terhadap novel The Buddha in the Attic karya Julie Otsuka ini terdiri dari tiga tahap. Pertama, analisis secara tekstual mengenai kehidupan sebagai picture brides dan imigran Jepang di Amerika ditampilkan dalam novel. Pada tahap kedua, pembacaan paralel antara teks dan konteks sejarah dilakukan.

\section{HASIL DAN PEMBAHASAN}

\section{Kehidupan sebagai Japanese Picture Brides di Amerika Serikat}

Sebagai sebuah mitos yang telah melekat dalam karakteristik Amerika Serikat, American Dream memang terkesan menawarkan kesempatan bagi mereka yang ingin mewujudkan impian-impian yang tertunda. Akan tetapi, fakta bahwa imigran Jepang merupakan kelompok minoritas, kemungkinan untuk mengalami kenaikan struktur kelas sosial amatlah kecil bagi kelompok ini. Kondisi ini nampak dalam kehidupan para picture brides Jepang dan keluarga mereka yang jauh dari kesan sukses.

Saat menjejakkan kaki untuk yang pertama kali di daratan Amerika, para picture brides ini menyadari jika mereka telah tertipu dengan ilusi yang diberikan oleh foto-foto calon suami mereka. Para laki-laki yang mengaku sebagai sosok sukses di Amerika ternyata adalah para buruh perkebunan dan berusia paruh baya. Laki-laki yang menjemput mereka di pelabuhan adalah orang-orang yang berbeda dengan foto yang mereka dapatkan karena segerombolan pria bertopi rajut butut dan berjaket hitam kumal yang tengah menanti mereka di dermaga sama sekali tidak mirip dengan pria-pria muda dan tampan difoto yang mereka bawa. Dihadapkan pada situasi yang tidak memberikan pilihan lain, maka mereka pun menundukkan kepala mereka sembari mengusap rok kimono mereka dan tetap menghampiri pria-pria tersebut. Para perempuan ini berpendapat bahwa "ini adalah Amerika, aku tidak perlu takut atau khawatir" (Otsuka, 2011: 33).

Para picture brides ini kemudian mengalami serangkaian peristiwa malang setelah mencapai daratan Amerika. Apa yang mereka harapkan sebagai sebuah "pelarian" dari belenggu kehidupan desa ternyata hanyalah bualan belaka. Suami yang menjanjikan kehidupan mewah dan nyaman di Amerika ternyata hanya mampu memberikan kehidupan di pinggiraan kota sebagai buruh perkebunan dan bahkan sebagian 
malah menjual mereka ke rumahrumah pelesir (Otsuka, 2011).

ONE OF THEM bought us out of the brothel where we worked and brought us home to a big house on a tree-lined street in Montecito, whose name we shall not reveal. ... SOMETIMES, while we were lying with them, we found ourselves longing for our husbands, from whom we had run away. Was he really so bad? So brutal? So dull? Sometimes we found ourselves falling in love with our bosses, who had kidnapped us at knifepoint as we were coming in from the fields. He brings me things. He talks to me. He lets me go for walks. Sometimes we convinced ourselves that after one year at the Eureka House we would have enough money to pay for our passage back home, but at the end of that year all we had was fifty cents and a bad dose of the clap. Next year, we told ourselves. Or maybe the year after that. But even the prettiest of us knew that our days were numbered, for in our line of work you were either finished or dead by the time you were twenty (Otsuka, 2011: 75-77).

Akan tetapi, keinginan untuk kembali ke negara asal mereka tetap menjadi bayang-bayang dikehidupan mereka. Sebagian besar dari picture brides ini bahkan mencoba mengobati kerinduan mereka dengan menyanyikan lagu panen dari masa kecil mereka sembari membayangkan mereka sedang berada di rumah keluarga mereka. Lambat laun, rasa rindu itu pun menghilang dan berganti dengan obsesi untuk bekerja lebih tekun dan lebih keras. Dengan bekerja nyaris tanpa henti sepanjang hari, mereka pun mulai mendapatkan validasi dari majikan mereka karena postur tubuh mereka yang kecil dan kemampuan untuk bertahan dibawah teriknya matahari. Tetapi mereka juga mengalami perlakuan tidak menyenangkan dari orang Amerika, seperti mendapati ladang mereka dihancurkan maupun mendapati unggas-unggas yang menjadi hewan ternak mereka habis terbakar saat mereka tengah terlelap dimalam hari. Perlakuan tidak menyenangkan yang dialami pada para picture brides ini memaksa mereka untuk pindah ke pinggiran kota untuk menjadi pelayan dan peternak (Otsuka, 2011).

Sebagian dari picture brides ini juga pindah ke J-Town dimana mereka membuka usaha binatu dan membentuk sebuah komunitas warga Jepang di Amerika. Akan tetapi, tatapan aneh dari orang disekitar mereka tetap tidak dapat mereka hindari setiap kali mereka keluar dari J-Town. Meskipun para perempuan ini telah berpakaian dengan baju setelan (two pieces clothes) dan berjalan dengan langkah lebar layaknya orang Amerika, mereka tetap mengundang perhatian orang-orang disekitar mereka. Perilaku ini dipahami sebagai sebuah upaya untuk meniru kelompok dominan, yaitu orang Amerika berkulit putih yang menjadi penduduk mayoritas di Amerika. Tindakan yang demikian, dikenal dengan konsep melting pot dan acap kali dilakukan oleh para imigran yang menetap di Amerika sebagai sebuah upaya agar 
mereka dianggap sebagai warga negara Amerika Serikat (Americans).

Proses melting pot ini juga disebut sebagai Americanization yang disinyalir sebagai sebuah upaya untuk menjaga budaya Amerika agar tetap homogen (Gloor, 2006). Senada dengan pendapat ini, Kivisto (2004) mengkritik bahwa melting pot sejatinya merefleksikan budaya dari masyarakat yang dominan, bukan sebagai sebuah bentuk masyarakat yang terintegrasi dari beberapa budaya yang saling membaur. Sebabnya, bentuk asimilasi kebudayaan yang demikian dipandang sebagai jalan satu arah karena bergantung pada kooperativitas para imigran yang diorientasikan untuk menyerupai kultur dominan dari masyarakat British American atau warga Amerika berkulit putih. Fenomena yang demikian disebut juga dengan istilah Anglo-conformity dan bertujuan untuk menjaga homogenitas budaya di Amerika Serikat.

\section{Picture Brides dan Imigran Jepang sebagai kelompok Subaltern}

Sebagai sebuah bentuk kesadaran kolektif, American Dream secara sederhana didefinisikan sebagai sebuah kepercayaan yang meyakini bahwa semua individu memiliki kesempatan yang setara untuk mencapai kesuksesan dan kebahagiaan. Namun, untuk mewujudkan kesuksesan seperti yang ditawarkan oleh konsep American Dream ini, tidaklah semudah klaim The Declaration of Independence (1776) yang menyatakan bahwa tiap-tiap individu pada dasarnya memiliki status yang setara dan diberkati dengan hak-hak kemanusiaan yang meliputi hak untuk hidup (life), mendapat kebebasan (liberty) dan menggapai kebahagiaan (pursuit of happiness) (Jefferson, 1776).

Akan tetapi, perlu disadari pula bahwa isi dari deklarasi kemerdekaan merupakan kalimat-kalimat yang terkesan menjanjikan. Apabila diteliti lebih dalam lagi, isi dari deklarasi ini secara implisit menggaungkan American Dream yang menekankan pada agensi individu yang berujung pada kemapanan bagi diri sendiri (personal fulfiment). Hal ini dikenal juga dengan istilah patriotic rhetoric yang menginspirasi masyarakat untuk mewujudkan American Dream. Namun, hal ini tidak sepenuhnya benar karena hal-hal yang berkaitan dengan jargon life, liberty, dan the pursuit of happiness akan selalu berkaitan dengan kelompok dan kelas sosial, dan bukanlah upaya individu. Individu sebagai anggota sebuah kelompok sosial hanya akan mengalami kenaikan kelas sosial apabila kelompok sosial yang menjadi dasar pergerakan sosial mengalami pergerakan kelas sosial.

Pergerakan kelas sosial di Amerika Serikat sejatinya akan selalu berkaitan dengan status rasial. Rasisme secara tidak langsung diimplementasikan sebagai sebuah cara untuk menjaga struktur sosial di Amerika. Dominasi rasial oleh warga kulit putih secara tidak langsung turut menjadi bagian dalam proses pembangunan bangsa dan negara di Amerika Serikat. Dengan kata lain, rasisme menjadi sebuah hal yang secara terus menerus mempengaruhi identitas nasional. Dari kondisi muncullah sebuah stigma bahwa imigran, sebagai kelompok inferior apabila dibandingkan dengan warga kulit putih. 
$\begin{array}{ccr}\begin{array}{c}\text { Seperti } \\ \text { dipaparkan }\end{array} & \begin{array}{r}\text { yang } \\ \text { pada }\end{array} & \begin{array}{r}\text { telah } \\ \text { bagian }\end{array}\end{array}$ sebelumnya, untuk mendapatkan validasi dari kelompok mayoritas atau dominan, para picture brides beserta imigran Jepang ini melakukan berbagai macam upaya adaptasi. Tidak hanya mengubah gaya berpakaian dan mempelajari Bahasa Inggris, mereka juga bungkam terhadap segala perlakuan rasis dan tidak menyenangkan yang dilakukan oleh masyarakat Amerika di sekitar mereka. Tindakan para imigran Jepang ini kemudian menimbulkan adanya persepsi bahwa warga Jepang merupakan sosok yang docile. Berawal dari persepsi ini, muncul sebuah stereotype terhadap imigran Jepang yang dikenal dengan model minority, seperti nampak pada kutipan berikut:

We settled on the edges of their towns, when they would let us. And when they would not-Do not let sundown find you in this county, their signs sometimes said-we traveled on. We wandered from one labor camp to the next in their hot dusty valleys - the Sacramento, the Imperial, the San Joaquinand side by side with our new husbands, we worked their land. We picked their strawberries in Watsonville. We picked their grapes in Fresno and Denair. We got down on our knees and dug up their potatoes with garden forks on Bacon Island in the Delta, where the earth was spongy and soft. On the Holland Tract we sorted their green beans. And when the harvest season was over we tied our blanket rolls onto our backs and, cloth bundles in hand, we waited for the next wagon to come, and we traveled on (Otsuka, 2011:40).

Dari kutipan tersebut, nampak bahwa para picture brides dan imigran Jepang ini digambarkan sebagai sosok yang docile dan enggan melawan. Gambaran ini merupakan contoh dari stereotype model minority yang melekat pada kelompok imigran Asia Timur.

Stereotype model minority ini dapat dikatakan sebagai bentuk reduksi dari nilai-nilai American Dream yang selama ini menjadi kesadaran kolektif masyarakat Amerika. Dengan kata lain, nilai awal American Dream yang menjunjung tinggi life, liberty dan the pursuit of happiness ini justru menciptakan gap atau perbedaan rasial yang mencolok menyebabkan adanya inferioritas imigran Jepang terhadap ras kulit putih di Amerika. Status sosial ini secara tidak langsung memaksa para imigran Jepang untuk diam mengenai hak politik dan ekonomi mereka yang secara diam-diam direnggut oleh pemerintah Amerika Serikat. Misalnya, Issei yang masih berstatus kewarganegaraan Jepang dan Nissei yang berstatus kewarganegaraan Amerika, tidak mendapatkan hak-hak mereka untuk memiliki lahan atau mendapat pendidikan yang layak, meskipun telah ikut berperan dalam proses pembangunan di Amerika.

Sebagai sebuah bentuk kesadaran sosial yang telah melekat dalam kehidupan masyarakat Amerika, American Dream dipandang sebagai sebuah acuan dalam berbagai aspek kehidupan. Selain berkaitan dengan 
kebahagiaan materi, American Dream juga berkaitan dengan nilainilai kebebasan. Nilai kebebasan inilah yang kemudian dinegasi oleh pemerintah Amerika Serikat untuk memperalat imigran Jepang di Amerika. Dengan menciptakan regulasi-regulasi yang mewajibkan individu di Amerika sebagai warga negara Amerika yang resmi dan diakui oleh negara, nampak sebuah siasat pemerintah untuk mengontrol individu-individu yang ada di Amerika. Dari penjelasan tersebut, perilaku subversif yang ditunjukkan oleh para imigran Jepang di Amerika maupun merupakan hasil dari reduksi nilainilai American Dream.

Disisi lain, reduksi nilai-nilai American Dream ini juga menyebabkan beredarnya The Yellow Peril di penjuru Amerika, warga Amerika yang semula bersikap netral kepada imigran Asia Timur menjadi berpandangan rasis karena adanya rumor yang menyebutkan bahwa warga Asia Timur merupakan sosok liar dan merupakan the lesser breeds. Dengan adanya ketakutan irasional ini, warga Amerika memperlakukan imigran Asia layaknya alien sehingga merugikan para imigran Asia Timur seperti nampak pada kutipan berikut:

THEY DID NOT want us as neighbors in their valleys. They did not want us as friends. We lived in unsightly shacks and could not speak plain English. We cared only about money. Our farming methods were poor. We used too much water. We did not plow deeply enough. ...
MANY NIGHTS, we waited for them. Sometimes they drove by our farm shacks and sprayed our windows with buckshot, or set our chicken coops on fire. Sometimes they dynamited our packing sheds. Sometimes they burned down our fields just as they were beginning to ripen and we lost our entire earnings for that year. And even though we found footsteps in the dirt the following morning, and many scattered matchsticks, when we called the sheriff to come out and take a look he told us there were no clues worth following. And after that our husbands were never the same. Why even bother? (Otsuka, 2011:58-59).

Lebih lanjut, sebagai sebuah bentuk propaganda rasisme yang mendiskreditkan warga Asia Timur, The Yellow Peril sejatinya menyiratkan praktek esensialisme strategis. Dalam fungsi praktisnya, esensialisme strategis merupakan tindakan politis yang bertujuan untuk melemahkan kelompok subaltern. Dengan melemahkan kelompok subaltern, maka akan mudah bagi pemerintah Amerika Serikat untuk memanfaatkan kelompok subaltern. Tindakan pemerintah Amerika Serikat yang dengan sengaja membiarkan beredarnya rumor The Yellow Peril merupakan bentuk penerapan kekerasan epistemis yang mendistorsi cara pandang warga Amerika.

Secara diam-diam, warga Amerika dimanipulasi agar hanya memiliki satu cara pandang. Dengan memiliki satu cara pandang terhadap imigran Asia Timur, maka warga Amerika tidak menyadari adanya 
bentuk praktek diskursif yang tengah dilakukan oleh pemerintah Amerika Serikat. Tindakan mengumbar The Yellow Peril yang dilakukan oleh pemerintah ini menggiring warga Amerika untuk percaya bahwa mereka adalah kelompok yang lebih unggul dibandingkan para imigran Asia Timur, sehingga layak dijadikan acuan bagi para imigran Asia Timur di Amerika. Dengan memberikan hak-hak lebih terhadap warga Amerika berkulit putih, secara tidak langsung, nilai-nilai American Dream yang berkaitan dengan life, liberty dan the pursuit of happiness hanya dapat dicapai oleh mereka yang dianggap sebagai warga Amerika (All-American).

Dari kedua fenomena rasisme yang nampak ini, dapat dikatakan bahwa ada tindakan saling menegasi identitas yang disebabkan oleh reduksi nilai-nilai American Dream. Reduksi nilai-nilai American Dream yang menjunjung keseteraan untuk mewujudkan impian masing-masing individu secara politik diubah oleh Pemerintah Amerika Serikat untuk menciptakan batasan-batasan berdasarkan ras. Dari tindakan ini, muncul antagonisasi antar ras di Amerika Serikat sehingga terciptalah negasi identitas. Proses saling menegasi ini juga dikenal sebagai dengan othering, Kelompok imigran Jepang, termasuk didalamnya para picture brides, sebagai kelompok subaltern menduduki status sebagai the others. Mereka dipandang sebagai sosok subjek yang sudah selayaknya tunduk pada kelompok the Others, atau warga Amerika berkulit Putih, yang statusnya jauh lebih dominan dibandingkan para picture brides dan imigran Jepang lainnya.

Pergerakan kelas sosial yang sejatinya didasari dengan validasi kelompok dan status sosial para imigran Jepang di Amerika memunculkan batasan-batasan bagi kedua kelompok yang berbeda identitas ini. Konstruksi ini kemudian melekat dan menjadi label identitas bagi para imigran Jepang di Amerika. Untuk menghilangkan batasanbatasan ini, kelompok subaltern berusaha mengadaptasi kebudayaan kelompok dominan dengan harapan mendapatkan validasi. Dengan adanya anggapan bahwa budaya dominan adalah sebuah norma, kelompok subaltern ini, mau tidak mau, akhirnya tunduk dan mengadaptasi budaya dominan. Dari proses othering ini, secara tidak langsung, homogenitas budaya kelompok dominan dilanggengkan.

\section{SIMPULAN}

The Buddha in the Attic juga menunjukkan bagaimana sebuah karya sastra diciptakan dalam konteks politik. Hal ini nampak dengan bagaimana American Dream yang semula merupakan gaung untuk mencapai kesuksesan bagi imigranimigran Jepang yang datang ke Amerika, ternyata berbanding terbalik dengan kenyataan yang mereka alami. American Dream yang semula merupakan gaung kesuksesan berubah menjadi sebuah alat propaganda pemerintah Amerika Serikat. Negasi identitas yang tercipta dari stereotype warga Jepang dan warga Amerika berkulit putih menunjukkan adanya reduksi nilai-nilai American Dream. Proses saling menegasi inilah yang menandakan adanya fenomena kelompok imigran Jepang sebagai 
kelompok subaltern di Amerika. Para picture brides dan juga imigran Jepang di Amerika sebagai kelompok subaltern yang mengalami proses othering ini berusaha mengadaptasi kebudayaan kelompok dominan dengan harapan mendapatkan validasi di Amerika Serikat. Dengan demikian, reduksi nilai-nilai American Dream yang dilakukan oleh pemerintah Amerika Serikat merupakan sebuah medium untuk menjaga homogenitas budaya di Amerika.

\section{DAFTAR PUSTAKA}

Adams, J. T. 1931. The Epic of America. Boston: Little Brown \& Co.

Amadeo, K. 2019. What Is the American Dream? The History That Made It Possible. Dipetik April 13, 2019, dari The Balance: https://www.thebalance.co $\mathrm{m} /$ what-is-the-americandream-quotes-and-history3306009

Bush, M. E. 2010. American Dream or Global Nightmare? Journal of Global Initiatives: Policy, Pedagogy, Perspective: Vol. 3: No. 2 , 135-149.

Chomsky, N. 2017. Requiem for the American Dream. New York: Seven Stories Press.

Clark, W. A. 2003. Immigration and the American Dream. Dalam W. A. Clark, Immigrants and the American Dream: Remaking the Middle Class (hal. 128). New York: Guilford Publications.

Creswell, J. W. 2007. Qualitative Inquiry \& Research Design (Choosing Among Five
Approaches). Thousand Oaks: SAGE Publications.

Cullen, J. 2003. THE AMERICAN DREAM: A Short History of an Idea That Shaped a Nation. Oxford: Oxford University Press.

Fagler, J. 2018. The "Picture Bride Problem": Experiences of and Attitudes Toward Japanese Picture Brides in California 1908-1920. Dissertation. Georgetown: Georgetown University Press.

Gloor, L. B. 2006. From the Melting Pot to the Tossed Salad Metaphor: Why Coercive Assimilation Lacks the Flavors Americans Crave. Vol. 04, 29-32.

Hallam, J. 2004. Slavery and The Making of America. Dipetik May 01, 2019, dari Thirteen Media with Impact:

https://www.thirteen.org/wne $\mathrm{t} /$ slavery/experience/family/h istory.html

Hocensky, T. 2015. The Concept of American Dream in $S$. Fitzgerald's The Great Gatsby and A. Miller's Death of a Salesman. Preddiplomski Studij, 1-2.

Jefferson, T. (1776). The Declaration of Independence 4th July 1776. Dipetik May 01, 2019, dari National Humanities Center: americainclass.org

Kaplan, L. E. 2009. The Making of the American Dream: An Unconventional History of the United States from 1607 to 1900. New York: Algora Publishing.

Kivisto, P. 2004. What is the Canonical Theory of Assimilation? dalam Journal of the History of the Behavioral Sciences 40.2, 149163. 
Kramer, L., \& Maza, S. 2006. A Companion to Western Historical Thought. Malden: Blackwell Publishing.

Lee, C. 2003. Prostitutes and Picture Brides: Chinese and Japanese Immigration, Settlement, and American Nation Building, 1870-1920. Working Paper 70, 1-47.

Leonte, E. 2017. Enacting the Silence of Subaltern Women: Julie Otsuka and Japanese Picture Brides. Master Thesis. Stockholm: University of Stockholm.

Okihiro, G. Y. 2001. The Columbia Guide to Asian American History. New York: Columbia University Press.

Otsuka, J. 2011. The Buddha in the Attic. New York: Alfred A. Knopf.

Ratna, N. K. 2015. Teori, Metode dan Teknik Penelitian Sastra. Yogyakarta: Pustaka Pelajar.

Roy, P. 1989. A White Man's Province: British Columbia Politicians and Chinese and Japanese Immigrants, 18581914. Vancouver: University of British Columbia Press.

Sato, K. 2015. 「写真花嫁」と『写 真花嫁』一佐藤 (trans.

'Picture Bride' and Picture

Brides: Between Fact and Fiction) dalam 山形大 学紀 要（人文科学）第 15 巻第 2 号 , 123-136.

Singh, A., Skidmore, M. J., \& Sequira, I. 1995. American Studies Today: An Introduction to Methods \& Perspective. New Delhi: Creative Books.

Spivak, G. C. 1987. In Other Worlds: Essays in Cultural Politic. New York: Routledge.
Spivak, G. C. 1990. The Post-Colonial Critic: Interviews, Strategies, Dialogues. New York \& London: Routledge.

Spivak, G. C. 1994. "Can the Subaltern Speak?" dalam Colonial and Post-Colonial Theory. New York: Columbia University Press.

Tanaka, K. 2000. Photographs of Japanese Picture Brides: Visualizing Immigrants and Practicing Immigration Policy in Early Twentieth-Century United States. Dalam U.S Immigration in Global Context (hal. 27-57). New York: Routledge.

Tanaka, K. 2009. Marriage as Citizen's Privilege: Japanese Picture Marriage and American Social Justice. NANZAN REVIEW OF AMERICAN STUDIES, 131-150.

Tittenbrun, J. 2015. The Myth of American Dream. World Scientific News, 1-16.

Toby, R. P. 2019. Engaging the Other: "Japan" and Its Alter Egos, 15501850. Leiden: Brill.

Tsutsui, W. M. 2007. A Companion To Japanese History. Oxford: Blackwell Publishing Ltd.

Yamamoto, T. 1999. Masking Selves, Making Subjects: Japanese American Women, Identity, and the Body. Berkeley: University of California Press.

Yanagisawa, I. T. 2010. 「写真花嫁」 たちのオーラル・ヒストリー

一カリフォルニア州立大学サ クラメント校一世オーラル・ ヒストリー・プロジェクトよ り (trans) Oral Histories of -Picture brides\|. Issei Oral History Project, Japanese American Archival Collection California State University, 6174. 